DOSSIER

Artículo de reflexión

\title{
La condición humana como política de la vida $^{1}$
}

\section{The human condition as a politics of life}

\section{A condição humana como política da vida}

\section{Luisa Fernanda Betancur Hernández ${ }^{2}$}

Para citar este artículo: Betancur, L. F. (2019). La condición humana como política de vida. Ciudad Paz-ando, 12(1), 56-66. doi: https://doi.org/10.14483/2422278X.13688

Fecha de recepción: 12 de julio de 2018

Fecha de aprobación: 18 de marzo de 2019

\footnotetext{
1 El presente artículo de reflexión es producto del segundo capítulo de la tesis de maestría en Filosofía llamada De una política de la muerte a una política de la vida. Una mirada al pensamiento político de Hannah Arendt. A partir de este trabajo investigativo se argumentó el paso de una política de la muerte a una política de la vida desde los dos textos de la pensadora alemana: Los orígenes del totalitarismo y La condición humana, revelando desde este segundo capítulo los postulados de la autora sobre la condición humana que permite la existencia del hombre en el mundo. Esta existencia en el mundo pretende una condición humana de la acción efectuada en la pluralidad de los asuntos humanos y en la política como garante del dialogar y el estar juntos en el entre-nos. Con la política de la vida se pretende contrarrestar esa política de la muerte emergida de los totalitarismos europeos donde la vida y el espacio de aparición entran a ser parte de la acción política y de la pluralidad en la esfera pública. Este segundo artículo es la continuación de uno anterior llamado "El terror en los orígenes del totalitarismo y la política de la muerte", que hace referencia al primer capítulo de la tesis anteriormente mencionada.

2 Magíster en Filosofía, Universidad Pontificia Bolivariana, Medellín. Docente de cátedra, Tecnológico de Antioquia Institución Universitaria. Correo electrónico: lbluisafernanda@gmail.com
} 


\section{RESUMEN}

Con La condición humana, Hannah Arendt propuso identificar la posibilidad de la existencia humana a partir de las relaciones políticas en la esfera pública. Los totalitarismos europeos habían devastado a la humanidad en todas sus dimensiones, la barbarie había focalizado a la violencia como método de exterminio para afianzar una política de la muerte desde ideologías políticas; pensando en lo anterior, se plantea el siguiente cuestionamiento: ¿por qué plantear la condición humana como la propuesta arendtiana de una política de la vida que hace frente a los totalitarismos? Se evidencia la importancia de un análisis hermenéutico cualitativo, a la vez que se analizan elementos tan indispensables como el pensamiento, el discurso, lo político, la diversidad y la pluralidad, los cuales hacen constar que la política de la vida es vital para las relaciones humanas si se piensa llegar a establecer lazos políticos reflexivos que ayuden a emerger consensos entre los seres humanos.

Palabras clave: acción política, condición humana, Hannah Arendt, pluralidad, política de la vida, vita activa.

\section{ABSTRACT}

With The Human Condition, Hannah Arendt proposed to identify the possibility of human existence starting from political relations in the public domain. European totalitarianism had devastated humanity in all aspects, barbarism had stablished violence as a method to exterminate and reassure a political force of death from political ideologies. On the previous idea, the following question comes up: why think of human condition as an Arendt idea that highlighting life will stand up against totalitarianism? The importance of a hermetic qualitative analysis is evident and at the same time to analyze key elements such as thinking, speech, political view, diversity and pluralism, which prove that highlighting life is vital for human relations if one thinks on stablishing reflexive political links to help bring about general agreements between human beings.

Keywords: political action, human condition, Hanna Arendt, pluralism, politics of life, vita activa.
Com $A$ condição humana, Hannah Arendt propôs identificar a possibilidade da existência humana a partir das relações políticas na esfera pública. Os totalitarismos europeus haviam devastado a humanidade em todas as suas dimensões, a barbárie tinha se concentrado na violência como um método de extermínio para fortalecer uma política de morte a partir das ideologias políticas; pensando no exposto acima, coloca-se a seguinte questão: por que levantar a condição humana como proposta arendtiana de uma política de vida que enfrenta o totalitarismo? A importância de uma análise hermenêutica qualitativa é evidente, ao mesmo tempo em que elementos essenciais como pensamento, discurso, política, diversidade e pluralidade são analisados, o que torna claro que a política da vida é vital para as relações humanas se se pretende estabelecer laços políticos reflexivos que ajudem a emergir consenso entre os seres humanos.

Palavras-chave: ação política, condição humana, Hannah Arendt, pluralidade, política de vida, vita activa. 


\section{Introducción}

El presente prolegómeno representa la importancia de la vida misma en el contexto humano, sobre todo, el de la esfera pública donde se evidencia la capacidad de actuar junto al otro y aceptar la diversidad que los aúna, pero que al mismo tiempo los diferencia. Para Arendt, la condición humana no solo radica en la misma apariencia humana, la labor biológica del cuerpo y el trabajo de las manos se incluyen en esa condición de vida que hace a los hombres libres y plurales en el mundo. Con la acción, la condición humana expresa lo más humano de la especie, pues la transformación del contexto y el relacionarse con los demás en un mundo político implica que lo público sea inherente a la acción de los hombres y a su trasegar histórico; por lo tanto, cabe afirmar que, conceptos como labor, trabajo y acción se deben desarrollar a partir de la confluencia de la vida misma como una opción intencional para la participación de los hombres en un mismo contexto y con unos fines que pueden ser disímiles o iguales.

Una política de la vida a partir de lo diverso configura al espacio público en ese lugar de encuentro y aparición que les proporciona a los hombres la pluralidad y la capacidad de ejercer discurso en un mundo en libertad, apreciando el esparcimiento y la perseverancia que puede otorgar la acción. La inmanencia del discurso devela la comunicación universal que transforma las cosmovisiones y pone en entredicho la singularidad de cada hombre y mujer dentro de un sistema político. Con la condición humana ya no existe el aislamiento profundo que se vivía en los totalitarismos, la esfera pública va a tomar parte en la unión de los hombres en un mismo espacio, pero con ideas diferentes, lo cual hace posible que el poder político de cada uno sea consecuente con la experiencia y la cotidianidad. Los asuntos humanos se aprecian desde una panorámica exhaustiva que influye en el devenir de la vida y del estar juntos como un colectivo.

Para contrarrestar una política de la muerte se planteó un cuestionamiento que evidenciara las acciones de los totalitarismos como referentes de terror y animadversión en occidente, es así como, con base en la pregunta manifiesta, se desarrollan en el artículo los siguientes apartados que dan continuidad al análisis hermenéutico del pensamiento político de Hannah Arendt, la vita activa: una posibilidad para el hombre en la esfera pública; la labor y el trabajo en la sociedad; la acción y el discurso en la pluralidad de los hombres; hacia una política de lo diverso y visión antropológica de una política de la vida.

\section{La vita activa: una posibilidad para el hombre en la esfera pública}

Lo que da al ser humano su humanidad-así como su inhumanidadno es una esencia metafísica, sino la relación con el otro.

Joan-Carles Mèlich
Las posibilidades políticas del hombre occidental en la esfera pública residen en la preponderancia del acontecer y del permanecer juntos en un mismo espacio y tiempo. La polis griega fue uno de los mayores ejemplos de contextualización entre los hombres que convivían política y conjuntamente en un mismo espacio como hombres libres y equivalentes en su estatus y quehaceres cotidianos, la expresión vita activa denotaba inquietud en la sociedad griega de la antigüedad; desde allí se erigían las normas que iba a ejecutar toda una sociedad y en la que los asuntos públicos representaban el núcleo principal de este tipo de vida. Hannah Arendt (2005), en su texto de La condición humana, afirma lo siguiente de la vita activa:

Con la expresión vita activa me propongo designar tres actividades fundamentales: labor, trabajo y acción. Son fundamentales porque cada una corresponde a una de las condiciones básicas bajo las que se ha dado al hombre la vida en la tierra. (p. 35)

La estrategia de la vita activa es concebir una importancia histórica y social a la existencia de los seres humanos por medio de estos tres factores, otorgándole a la humanidad la oportunidad de destacar la complejidad de la labor de su cuerpo, la transformación que otorga el trabajo de sus manos y la pluralidad en la esfera pública que se manifiesta mediante la acción en la condición humana. Con la labor no se puede olvidar su reciprocidad con el sobrevivir y el permanecer en el orbe, pues su condición en la vida pública hace pervivir la naturaleza del metabolismo humano en consonancia con el desarrollo físico del mismo. El trabajo en sí propicia la conclusión de lo que hacen y transforman las manos con el entorno natural; el homo faber realiza su aporte a la constitución económica y tampoco se exime de entrar a ser parte de los innovadores procesos de reificación social. Con la acción se efectúa la pluralidad en un escenario como la esfera pública, donde se percibe el discurso existente entre los hombres y las implicaciones políticas de la toma de decisiones mediante la aparición de los otros y la particularidad que emerge desde cada uno de ellos.

Asimismo, la autora define a la vita activa como un concepto lleno de tradición histórico-filosófica que ha traspasado las fronteras políticas del hombre en su recorrido histórico:

La expresión vita activa está cargada de tradición de pensamiento político. Y dicha tradición, lejos de abarcar y conceptualizar todas las experiencias políticas de la humanidad occidental, surgió de una concreta constelación histórica: el juicio al que se vio sometido Sócrates y el conflicto entre el filósofo y la polis. Esto eliminó muchas experiencias de un pasado próximo que eran inaplicables a sus inmediatos objetivos políticos y prosiguió hasta su 
final, en la obra de Karl Marx, de una manera altamente selectiva. La expresión misma - en la filosofía medieval, la traducción modelo de la aristotélica bios politikos- se encuentra ya en San Agustín, donde como vita negotiosa o actuosa, aún refleja su significado original: vida dedicada a los asuntos públicos-políticos. (Arendt, 2005, p. 37)

La existencia del hombre indica que prevalece una unión trascendental con sus pares adyacentes a partir del aspecto político. El hombre en sociedad rehace un discurso propio y fundamenta sus actividades en el actuar con los demás, lo cual facilita la apertura de cambios sociales en consideración con un tiempo pasado y un tiempo presente que ayude a construir el futuro. La presencia de la imagen temporal en los hombres conlleva a sustraer elementos cognitivos y sociales que la historia y el tiempo han ayudado a construir, permitiendo la configuración del pensamiento humano que se encauza en el devenir de la sapiencia y del desarrollo de todas las esferas sociales. La humanidad es certera en sus consensos sociales, aportando un núcleo vital de la participación y de la actuación en las decisiones que se toman a través del tiempo, disponiendo de la palabra y de la comunicación que les permite dar cuenta de la historia y del propio mundo. Los seres humanos tienen la oportunidad de la palabra porque por medio de ella pueden considerar y diferir sus problemas, la palabra retoma el placer por el diálogo y la discusión en el ámbito de lo público, llevando a cabo una riqueza universal relacionada con la existencia y el reconocimiento de sí mismos:

La razón de que el hombre sea un ser social, más que cualquier abeja y que cualquier otro animal gregario, es clara. La naturaleza, pues, como decimos, no hace nada en vano. Sólo el hombre, entre los animales, posee la palabra. La voz es una indicación del dolor y del placer; por eso la tienen también los otros animales. ( $Y$ que por su naturaleza ha alcanzado hasta tener sensación del dolor y del placer e indicarse estas sensaciones unos a otros). En cambio, la palabra existe para manifestar lo conveniente y lo dañino, así como lo justo e injusto. (Aristóteles, trad. 1993, p. 1253a)

No solo la palabra determina la característica principal de los hombres frente su actuar juntos en relación con su aparición en la esfera pública. Cuando los hombres hacen su aparición, se origina la pluralidad diversa en sus pensamientos y el acontecer visionario que se realiza en el ámbito público, el cual se especifica en el mirarse y reconocerse como pares. La vita activa conlleva a presupuestar estrategias de convivencia y de acciones que, por medio de la apariencia, identifica los sentidos de percepción de una humanidad política. Hannah Arendt concibe a la aparición en la esfera pública como algo contingente desde la pluralidad:
No existe nada ni nadie en este mundo cuya misma existencia no presuponga un espectador. En otras palabras, nada de lo que existe es singular desde el momento en que hace su aparición; todo lo que es está destinado a ser percibido por alguien. No es el Hombre en mayúsculas, sino la totalidad de los hombres los que habitan este planeta. La pluralidad es la ley de la tierra. (2012, p. 43)

El otro en la aparición es contingente en la pluralidad de los asuntos humanos, pues la condición humana a partir de la existencia convive con las intenciones concluidas dentro de la esfera pública y los consensos sociales que surgen en las relaciones humanas.

La determinación de la condición humana en labor, trabajo y acción demuestran que la vita activa confirma una pluralidad entre los hombres y los lleva a establecer todo un compuesto de instituciones y organizaciones para encontrar una afinidad en sus relaciones interpersonales. La vita activa es disímil de la vita contemplativa, esta requiere quietud y solitud para la dedicación del pensamiento y la obra intelectual humana; aunque ambas sean diferentes son indispensables en la esfera pública y en la esfera privada de los hombres, ya que en ellas el desarrollo del pensamiento y de la dialogicidad conduce a establecer la razón. Hannah Arendt argumenta la diferencia entre esa vita activa y esa vita contemplativa: "La forma de vida activa es 'laboriosa', la contemplativa es pura quietud; la activa se despliega en público, la contemplativa en el 'desierto'; la activa se consagra a 'la necesidad del prójimo', la contemplativa a la 'visión de Dios'” (2012, p. 32). Con la comparación definitiva que hace Arendt en referencia a ambas vidas, se evidencia que las esferas pública y privada no dejan de ser contextos ventajosos para este tipo de actividades; estas experiencias en cuanto al orden social y deliberativo hacen que la vida humana tenga mayor eficacia y subjetividad en aquellos que las siguen.

La condición humana propicia la existencia en el mundo y la concordancia biológica, productiva y política de los hombres en su actuar; también propicia desde lo político una conveniencia de pluralidad y vida que permite que el hombre aprenda y participe de su existencia y de su ser como una parte esencial de la humanidad. Los asuntos humanos implican ese aprendizaje y esa participación en la importancia de estar vivos y compartir en un mismo espacio las diferencias y similitudes que están insertas en la cooperación y en lo político. Pero para la autora la condición humana no es lo mismo que la naturaleza humana, pues la condición humana pertenece más a la existencia y a su actuar para sobrevivir, en cambio, la naturaleza humana tiene unas connotaciones éticas y psicológicas que evidencian los imperativos categóricos entre los hombres y su incidencia tanto en lo privado como en lo público. 


\section{La labor y el trabajo en la sociedad}

La condición humana confiere un sentido de la existencia a los hombres y a su ciclo biológico como base de sobrevivencia. La condición humana de la labor realiza una paradigmática muestra de su esencia, de su preeminencia en la bitácora de la evolución humana y en la presencia de la misma vida como modo de objetivación del sobrevivir, con el trabajo se propone la transformación del contexto natural de los hombres y su incidencia en las estructuras económicas. El trabajo de las manos y su posterior transformación a una necesidad secundaria verifica el entramado complejo de los menesteres materiales y de las transacciones económicas en la vida productiva.

La labor biológica que forja el mismo cuerpo hace constar que esa vida ayuda en todos los procesos biológicos de la naturaleza. Las necesidades primarias que tiene el hombre con referencia a su cuerpo vitalizan la estructura fisiológica de todo su organismo, asimismo, evidencia su aporte a las otras dos condiciones de la existencia humana; con la labor también se propone la procreación y la perennidad de la especie dentro de un espacio y un tiempo destacable, así se afirma que la vida mediante la natalidad recrea la infinitud de la especie humana y su importancia en la vida política y social. Con la finitud se concreta el axioma de morir física y biológicamente, sobre lo cual el filósofo español Joan-Carles Mèlich habla como una interpretación del mundo en el cual se vive, donde la vida misma es un trayecto en un intervalo de tiempo:

En la interpretación comenzamos a descubrir una primera expresión de la presencia inquietante de la finitud. Si inevitablemente interpretamos el mundo es porque nunca somos absolutos, porque en el ser humano no hay acabado, porque no vivimos en un final de trayecto, sino en un trayecto, porque somos finitos. (Mèlich, 2012, p. 44)

Unos seres finitos que concluyen su vida en un mundo de oportunidades agrestes y que se configuran en un presente finito. La labor es una noción relevante en el acontecer humano, de ella depende la dinámica natural y de la propia vida que se encarga de que los ciclos anatómicos y fisiológicos trabajen a la perfección; para Arendt la labor es la condición sine qua non de la misma vida, por eso se ubica en el primer lugar de la condición humana:

Labor es la actividad correspondiente al proceso biológico del cuerpo humano, cuyo espontáneo crecimiento, metabolismo y decadencia final están ligados a las necesidades vitales producidas y alimentadas por la labor en el proceso de la vida. La condición humana de la labor es la misma vida. (Arendt, 2005, p. 35)

Puede tenerse también como esfuerzo de permanencia en la especie, y como experiencia de encuentro con los estímulos, motivaciones y razones que se convierten en aliento para conservarse en el hecho vivencial y sus circunstancias.

La vida y la muerte demuestran que los seres vivos están sujetos a las leyes de la naturaleza y del entramado biológico que visibiliza los metabolismos, pero la vida de los humanos no depende solamente de las leyes de la naturaleza, ya que la muerte también tiene su origen desde el contrato social de los hombres y de la complejidad de esos sistemas sociales que llevan a la violencia y a los asesinatos de unos contra otros como en la premisa de Thomas Hobbes homo homini lupus. El devenir de la vida y la muerte hacen parte de la finitud de los hombres debido a que el nacer, el crecer y el reproducirse son vitales en esa razón de existencia en la tierra y en el metabolismo que hace el cuerpo humano, por lo tanto, la política de la vida no solo debe dar permanencia a la existencia humana por medio de lo físico, la natalidad referida como el nacimiento de algo nuevo demuestra el simbolismo que tendrá a futuro esa vida inédita dentro de la política:

\footnotetext{
Mientras que la naturaleza se manifiesta en la existencia humana mediante el movimiento circular de nuestras funciones corporales, su presencia en el mundo hecho por el hombre la deja sentir en la constante amenaza de hacerlo crecer o decaer demasiado. La característica común del proceso biológico en el hombre y el proceso de crecimiento y decadencia en el mundo, consiste en que ambos son parte del movimiento cíclico de la naturaleza y, por tanto, interminablemente repetidos; todas las actividades humanas que surgen de la necesidad de hacerles frente se encuentran sujetas a los repetidos ciclos de la naturaleza y carecen en sí mismas de principio y fin, propiamente hablando; a diferencia del trabajar, cuyo final llega cuando el objeto está acabado, dispuesto a incorporarse al mundo común de las cosas, el laborar siempre se mueve en el mismo círculo, prescrito por el proceso biológico del organismo vivo, y el fin de su "fatiga y molestia" sólo llega con la muerte de este organismo. (Arendt, 2005, p. 120)
}

La finalidad de la labor en el animal laborans, mencionado por Arendt, no exceptúa la esencia de su propio cuerpo como una máquina que está en constante funcionamiento y que sostiene la amalgama de situaciones corporales que conllevan a la expresión máxima de la vida que es la procreación y los elementos prácticos y biológicos de la cotidianidad; por lo tanto, la política de la vida en relación con la labor, y al estar en consonancia con la naturaleza, determina que los hombres son proclives a la finitud de su existencia pero perfectos ante la labor de su cuerpo. Los organismos vivos permiten representar a la vida como tal desde un microbio hasta un ser humano que incluye los distintos estadios biológicos de su existencia. Marx acertó en la labor de una forma intestina por medio del trabajo - aunque más adelante se referirá al trabajo 
como otro elemento constitutivo de la condición humana-, muchas veces la labor del cuerpo se confunde con el proceso del trabajo y es así como se hace necesario abordar la labor como un proceso biológico que facilita otros motivos y procesos para sobrevivir.

Ahora bien, la labor ocupa un lugar privilegiado en la constitución de la vita activa de los hombres y de su funcionamiento vital biológico; con esta también llega la condición humana del trabajo, muy distinta a la anterior, ya que con el trabajo surge la transformación del medio natural gracias a las hacedoras manos de los hombres. El trabajo llega con preponderancia y magnificencia debido a que propone la renovación y no renovación de las materias primas, los objetos hechos y su posterior utilización en el contexto económico. El trabajo hace explícita la reificación o transformación de algún objeto anteriormente acabado y utilizado, pero que podría volver a tener un valor significativo como objeto reificado; asimismo, el trabajo de las manos del hombre se encauza dentro de un prodigio natural gracias a sus capacidades intelectuales y a la memoria histórica del desarrollo de la economía. Arendt indica a continuación la definición del trabajo en la sociedad:

Trabajo es la actividad que corresponde a lo no natural de la exigencia del hombre, que no está inmerso en el constante repetido ciclo vital de la especie, ni cuya mortalidad queda compensada por dicho ciclo. El trabajo proporciona un "artificial" mundo de cosas, claramente distintas de todas las circunstancias naturales. Dentro de sus límites se alberga cada una de las vidas individuales, mientras que este mundo sobrevive y trasciende a todas ellas. La condición humana del trabajo es la mundanidad. (Arendt, 2005, p. 35)

El trabajo siempre ha hecho parte de la vida del hombre, es por ello que lo necesita para sobrevivir en el contexto socioeconómico y para realizar sus intercambios comerciales con otros; con el trabajo el hombre se aísla para realizar su producto a través de sus manos, pero su esfera pública va a ser el mercado y el intercambio comercial con otros hombres que también se han aislado para hacer sus productos básicos, los cuales, en un tiempo posterior, tendrán el valor de ser utilizados en otras manos y en otras necesidades. El metabolismo que surge entre la naturaleza y el trabajo del hombre manifiesta la jerarquización de la especie humana como poseedora de la razón y de la transformación de los recursos naturales en elementos útiles para la vida del hombre. La ley de la historia y el conjunto socioeconómico que ha atravesado las circunstancias de todos los modos de producción y su repercusión en el desarrollo político de la humanidad develan la aparición del trabajo como ente de sobrevivencia ante el colectivo y las instituciones del Estado, como lo afirma Engels:
El trabajo es la fuente de toda riqueza, afirman los especialistas en economía política. Lo es, en efecto, a la par que la naturaleza, proveedora de los materiales que él convierte en riqueza. Pero el trabajo es muchísimo más que eso. Es la condición básica y fundamental de toda vida humana. Y lo es en tal grado que, hasta cierto punto, debemos decir que el trabajo ha creado al propio hombre. (Engels, 1978, p.5)

Lo anterior conlleva a cumplir con las normas económicas y la permanente expansión de la economía. El hombre tiene la capacidad de trabajar con sus extremidades, y aunque con la llegada de la revolución industrial la máquina pasa a hacer el trabajo que hacía el ser humano, este no quedó exento de seguir trabajando con sus manos por medio de la manufactura y en otros fines donde la era industrial no podía reemplazarlo por medio de la máquina.

El sobrevivir se ha convertido para el hombre en su telos primordial. Desde el sistema primitivo los hombres se han adaptado al medio ambiente efectuando una relación natural y consecuente con los procesos biológicos de la tierra donde se establecen, también como animal laborans influyen en las capacidades del comunicarse y de compartir entre los que conforman una comunidad. Con el trabajo se empiezan a constituir utensilios de valioso aporte para los hombres y su sobrevivencia en el medio ambiente, tal parece que el desarrollo cerebral del homo sapiens ha sido su mayor arma para el trabajo, el ingenio, la razón y el discurso. El objeto (cosa) que hace el hombre empieza a ser parte de esa fusión de elementos que sirven en la cotidianidad y en el mismo proceso del trabajo. Con Marx, el proceso del trabajo se ejemplifica de la siguiente manera:

En el proceso de trabajo la actividad del hombre consigue, valiéndose del instrumento correspondiente, transformar el objeto sobre el que versa el trabajo con arreglo al fin perseguido. Este proceso desemboca y se extingue en el producto. Su producto es un valor de uso, una materia dispuesta por la naturaleza y adaptada a las necesidades humanas mediante un cambio de forma. El trabajo se compenetra y confunde con su objeto. Se materializa en el objeto, al paso al que éste se elabora. Y lo que en el trabajador era dinamismo, es ahora en el producto, plasmado en lo que es, quietud. El obrero es el tejedor, y el producto el tejido. (Marx, 1984, p. 133)

La claridad de la influencia del trabajo en la sociedad concibe a la economía como el núcleo vital de toda esa tradición de consumo y de mercado que el trabajo produce como parte de la condición humana. El hombre por antonomasia como homo faber o transformador de su entorno aplica su fuerza corporal y el esfuerzo de su labor para dar continuidad y paso al producto que elabora, ya 
que los esfuerzos del creador son conjugados bajo un propósito y en su obra, elementos constitutivos que se determinarán dentro de lo que se le propone a la economía. El mérito del trabajo que realizan los hombres por medio de su fuerza identifica, de gran manera, la pertinencia de su producto terminado y de las demás fuerzas que estuvieron a su servicio en el proceso sistémico de lo que hacían sus manos y de lo que transformaban.

Con el producto final, el trabajo concibe permanencia en la premura de la utilización del objeto terminado. Las fuerzas que se conciben mediante el objeto dejan en claro que la participación de la transformación que realizan las manos del hombre y de la apetencia que ese mismo objeto genera incluye la independencia del objeto del hacedor o del trabajador que lo hace, la esencia de la transformación radica en la supremacía de las fuerzas corporales que presumen de su trascendencia y de su aporte al sistema económico, más que todo al señor que dirige al siervo en su trabajo. Hegel confirma la importancia del trabajo y la relación del trabajador y del objeto en su texto $L a$ fenomenología del espíritu:

El trabajo, por el contrario, es apetencia reprimida, desaparición contenida, el trabajo formativo. La relación negativa con el objeto se convierte en forma de éste y en algo permanente, precisamente porque ante el trabajador el objeto tiene independencia. Este término medio negativo o la acción formativa es, al mismo tiempo, la singularidad o el puro ser para sí de la conciencia, que ahora se manifiesta en el trabajo fuera de sí y pasa el elemento de la permanencia; la conciencia que trabaja llega, pues, de este modo a la intuición del ser independiente como de sí misma. (Hegel, 1978, p. 120)

El seguimiento de la transformación del entorno y de construir objetos que satisfagan las necesidades humanas comprende la perpetuidad e inmanencia de la labor y el trabajo del hombre en su contexto. La audacia de las manos y de las fuerzas humanas ha permitido la construcción de territorios que desde la esfera privada se autoricen elementos y transacciones económicas en la esfera pública, la esfera privada no concluye en los términos públicos de los contractualismos institucionales y cotidianos, antes bien, es necesaria para fundamentar la labor y el trabajo dentro de la existencia de los hombres. Se busca propiciar que los seres humanos vitalicen la esfera pública por medio de su razón y conciencia de sí para legar la labor y el trabajo como condiciones pertinentes y que anteceden a la condición de la acción.

La labor y el trabajo como entes fundamentales de la condición humana aportan en consideración una notable aparición del hombre en el mundo y en la sociedad. Las influencias de estos dos ámbitos en el desarrollo evolutivo de la especie humana se establecen junto con la condición humana de la acción y de la colectivización de los hombres, la cual propone y evidencia la trascendencia de las instituciones del Estado, la permanencia de los sistemas económicos y la organización social de los hombres como partidarios de consensos y decisiones que se toman en pro del beneficio colectivo.

\section{La acción y el discurso en la pluralidad de los hombres}

Con la acción, Hannah Arendt propone el último elemento de la condición humana y de la vita activa en la existencia de los hombres; la acción es específica en cuanto al rol que cumple dentro de la sociedad y le da forma a esa esfera pública y a la vida política que hace que los seres humanos sean capaces de relacionarse y ser plurales en el mundo.

Para que exista la acción es necesario que haya pluralidad en esa esfera pública. La pensadora alemana fue específica ante la definición de la acción, la cual siempre debe ir acompañada de la pluralidad entre los individuos y el vivir juntos en un mismo espacio, efectuando así relaciones de colectividad e identidad que posibiliten las garantías de los discursos y las actividades políticas en el contexto social correspondiente a su identidad colectiva. La acción, única actividad que se da entre los hombres sin la mediación de cosas y materia, corresponde a la condición humana de la pluralidad, actividad suprema que hace que los hombres vivan en la tierra y habiten el mundo. Mientras que todos los aspectos de la condición humana están de algún modo relacionados con la política, esta pluralidad es específicamente la condición -no solo la conditio sine qua non, sino la conditio per quam - de toda vida política (Arendt, 2005, p. 35).

La política de la vida que se propone en este abordaje no solo reside en la existencia de la humanidad mediante la labor y el trabajo que el hombre pueda desempeñar, la política de la vida en la acción va ligada a la oportunidad de reconocer al otro como un hombre que aparece en la sociedad para engendrar consensos, los cuales procuren entrever las diferentes necesidades que en todos los momentos de la vida se han padecido. La acción y la pluralidad hacen que el actuar juntos sea un medio afín que comunique la existencia de la humanidad y la haga presente en el ámbito de lo público.

La pluralidad en los asuntos humanos es exhaustiva como elemento de trascendencia y omnipresencia en todos los aspectos sociales. Sin lugar a duda, la pluralidad converge en el espacio del conocimiento y de la compasión como estrategia de igualdad y posibilidad para los hombres. Hannah Arendt fue enfática en relación con la pluralidad:

La pluralidad humana, básica condición tanto de la acción como del discurso, tiene el doble carácter de igualdad y distinción. Si los hombres no fueran iguales, no podrían entenderse ni planear y prever para el futuro las 
necesidades de los que llegarán después. Si los hombres no fueran distintos, es decir, cada ser humano diferenciado de cualquier otro que exista haya existido o existirá, no necesitarían el discurso y la acción para entenderse. (Arendt, 2005, p. 205)

La pluralidad emerge dentro de ese universo de posibilidades que otorga la identidad, así se confirma una vez más que la diferencia existente entre los hombres propone unas características principales en cada uno de ellos que se instala en la esfera pública y confluye en las comunicaciones específicas que desde allí se procuran. Los hombres consiguen mediante la acción configurarle atributos a los asuntos humanos como elementos significativos para la constitución de sociedades, acuerdos públicos y decisiones que devienen de lo particular y que hacen parte de lo colectivo y de la pluralidad, pero todo esto no puede ejecutarse sin el discurso, puesto que este permite el ser distinto en el espacio público, lo cual también interfiere con la pluralidad y la identidad de cada ser humano:

El interés se desplazó de la acción al discurso, entendido más como medio de persuasión que como específica forma humana de contestar, replicar y sopesar lo que ocurría y se hacía. Ser político, según Arendt, es vivir en una polis y, significa, que todo se decía por medio de las palabras y de persuasión, y no con la fuerza y la violencia. (2005, p. 53)

La pragmática del discurso en la esfera pública es un referente de pluralidad y de acción para concretar opciones de vida y evitar el aislamiento y los ataques que propiciaron los totalitarismos europeos, la dinámica del discurso emplea no solo la persuasión, sino la garantía de permanecer en ese espacio de aparición y del ser escuchado por los demás semejantes. Cuando los hombres se ponen en acción refieren un sinnúmero de particularidades, reflexiones y preferencias impartidas con la palabra y los cuestionamientos que surgen a partir de esas relaciones políticas, el modus vivendi que emerge de la acción acapara los argumentos que se obtienen en todos los aspectos sociales. Llegar a acuerdos es importante para la humanidad, sobre todo si se está en un espacio abierto que permita la dialogicidad y los valores éticos dentro del discurso y la pluralidad, así como lo describe Arendt:

El discurso y la acción revelan esta única cualidad de ser distinto. Mediante ellos, los hombres se diferencian en vez de ser meramente distintos; son los modos en que los seres humanos se presentan unos a otros, no como objetos físicos, sino qua hombres. Esta apariencia, diferenciada de la mera existencia corporal, se basa en la iniciativa, pero en una iniciativa que ningún ser humano puede contener y seguir siendo humano. (Arendt, 2005, p. 206)
La existencia humana comprende la trascendencia de la aparición en la esfera pública y el empoderamiento del discurso en la colectividad. La política de la vida debe permanecer en ese mundo de lo público donde se pueda observar la acción, la pluralidad y la vida que conserve la complejidad de cada hombre, pero que también propenda por la eficacia y la diferencia en las relaciones sociales; el espacio de aparición o la esfera pública hacen que se denote la dialogicidad y se proponga una vida pública política, convergente en la heterogeneidad de la vida y del actuar en sociedad para retornar a la política de la vida como estrategia de justicia y equidad entre los hombres.

\section{Hacia una política de lo diverso}

La vida transcurre en el acontecer de la esfera pública como mecanismo trascendental de la humanidad. Los hombres se confrontan mediante la aseveración de sus particularidades en cuanto a su aparecer en escena y como conjunto ante la inmanencia del tiempo, el estar vivo y el aparecer en la plaza pública significan estar a la vanguardia de las relaciones plurales y diversas que otorga la historia. Lo cotidiano se transmite en la aparición de los hombres como equivalentes en sus identidades y en sus actuaciones, permitiendo la cooperación y el reconocimiento de la individualidad de cada ser. El estar vivo es pervivir y sobrevivir en sistemas políticos y económicos que entretejen alteridades en las apariencias y en los imperativos culturales que hacen que la humanidad sea perenne en el planeta. Vivir en el mundo es para Arendt un "aparecer" notable en la esfera pública, lo cual posibilita la latente disposición de los hombres para su reunión colectiva como seres libres. Se procura la contingencia de las vidas y de las identidades en la pluralidad política:

Estar vivo significa vivir en un mundo anterior a la propia llegada y que nos sobrevivirá al partir. En este plano del simple "estar vivo", la aparición y la desaparición, en tanto que fenómenos recurrentes, son acontecimientos primordiales que, como tales, jalonan el tiempo; el tiempo transcurrido entre el nacimiento y la muerte. (Arendt, 2012, p.45)

Con los totalitarismos, la apariencia se cosifica en la muerte política y en el exterminio físico de la humanidad, allí se carece de la particularidad asombrosa y diversa del estar vivo y del reconocerse en el otro como una posibilidad de estar vivo, contingente en el espacio y en el tiempo. La no existencia de la pluralidad, sino de la masa y de la homogeneidad, pretendió coartar la imagen física del hombre, conllevándolo al trabajo forzoso que imponía un régimen totalitario con su sistema económico industrial; es aquí donde la no permisión de una vida política a través de la pluralidad se ve abocada a obedecer por medio del terror y de la ausencia de la identidad como una cifra más de un campo de concentración o como un ente 
que cumple su trabajo como imperativo de sobrevivencia; el aparecer en la política de la vida expresa la alteridad evidenciada en el entre-nos que se ejecuta en la esfera pública y en la existencia de la misma vida humana:

Por oposición al "estar- ahi" inorgánico de la materia inerte, los seres vivos no son meras apariencias. Estar vivo significa estar movido por una necesidad de mostrarse que en cada uno se corresponde con su capacidad para aparecer. Los seres vivos hacen su aparición como actores en un escenario preparado para ellos. El escenario es el mismo para todos los que están vivos, pero parece distinto para cada especie, diferente incluso para cada individuo. (Arendt, 2012, p. 45)

La diversidad se suma a esa política de la vida que refleja la pluralidad y la convivencia que los seres humanos identifican por medio de sus acciones. Ser diverso en la esfera pública implica responder a la diferencia y a lo diverso que cada hombre o mujer aporta con su propia existencia; conceptos como la identidad asumen una posición constante dentro de la sociedad, contribuyendo a idealizar unos parámetros colectivos que serían las relaciones de reciprocidad obtenidas mediante la pluralidad y el reconocimiento de que los demás son distintos pero que le aportan algo a las vidas de los otros.

La pluralidad, junto con la diversidad y la aceptación de los otros como personas diferentes, devela el aporte significativo que se hace el mismo colectivo social cuando entra a participar de la acción en la esfera pública; con ello se explica que la diferencia de credos, de gustos y demás eventos de los asuntos humanos permiten la disposición de nuevas lógicas discursivas que enriquecen el conocimiento y la solidaridad de los hombres en la esfera pública. La pluralidad y la diversidad ayudan a comprender que el hombre no puede vivir solo y que necesita del "otro" para poder pensar, innovar, dialogar y concebir decisiones que permanezcan en el tiempo, para así existir en una política de la vida. El estar juntos diversifica la pluralidad de los asuntos humanos y la certeza de compartir afinidades y diferencias que particularizan:

La pluralidad de los hombres y los pueblos, y su desigualdad fundamental; sin esta pura multiplicidad no habría ninguna política, sin esta desigualdad fundamental no se necesitaría ninguna ley; y el hecho de que "el amor necesita del amor", es decir, de que ningún hombre pueda existir solo, lo cual queda expresado en el doble sexo. Aquí el uno busca (o necesita) al segundo (y surge el tercero); y a la inversa, en el caso de la pluralidad el uno ha de contar ya siempre no con un segundo, sino con otros, $y$ está referido a ellos. (Arendt, 2005, p. 37)

Los asuntos humanos políticos son notables a la hora de entrar a modificar los diálogos y las relaciones entre los hombres. Cualquier hecho histórico ha requerido de la elocuencia del hombre para tratar de sobreponer todo aquello que se ha opuesto a la política de la vida, acabando con la diversidad e identidad sociales y que no han sido ajenos a las falacias de las determinaciones violentas. La identidad en la política de la vida asegura que cada individuo humano sobre la faz de la tierra deviene con sus particularidades y proezas a realizar acciones por y para el bien común; la identidad asemeja y discrepa de las diferencias anatómicas, emocionales y políticas de los hombres, pero al mismo tiempo hace que la esfera pública sea un universo de antagonismos complementarios pretendidos en un lugar y en un tiempo donde se compartan las mismas diferencias. Victoria Camps define la identidad de la siguiente manera:

Tener una identidad significa diferenciarse de la vulgaridad indiferenciada. Tener, además de nombre propio, profesión y residencia- las señas de identidad mínimas, la prueba objetiva de la diferencia y la igualdad jurídicas-, el sentido de la obligación de que hay que hacer de uno mismo una mujer o un hombre con cualidades, con una cierta talla, con una obra hecha. Tener una identidad es conferirle unidad a la propia vida, recoger el pasado y proyectarlo hacia adelante, fijar unos valores, marcar continuidades o transiciones. (Camps, 1996, p. 145)

Es preciso revelar esos valores que se construyen con la identidad. La vida misma acuerda con la identidad comprender la mismidad que caracteriza frente al mundo y hace concebir como personas diferentes en ese recorrido histórico; la identidad individual o privada, diferenciada de la nacional o de ser parte de una nación, pretende dignificar la figura de la política a partir de la pluralidad y de verse a sí mismo como un ser que piensa y actúa en conjunto para procurar el provecho que se vive en el ámbito de lo público y ser parte de esa sociedad que en el día a día transforma las relaciones políticas y sociales. Las dinámicas tejidas dentro de la política de la vida incorporan el carácter plural de las acciones humanas, de las experiencias de la justicia y de la equidad en vida de los hombres, estableciendo un campo de actuación en la esfera pública que no limite el permanecer juntos en el contexto político y que se evidencie la trayectoria de la pluralidad en las acciones cotidianas.

Por medio de la identidad y del estar presente en la vida de los demás es que puede combatirse ese aislamiento propuesto por los regímenes totalitarios donde la identidad basaba sus preceptos en la homogeneidad de las ideologías, de los partidos políticos y en la sociedad de masas que abarcaba un sinnúmero de individuos que no estaban atomizados pero que poseían la ausencia del pensamiento y de una ética propositiva de la vida. Las características de la heterogeneidad en la identidad y en la pluralidad de los asuntos humanos confirman la 
trascendencia que tienen la acción y el discurso en la esfera pública; es así que una política de la vida se hace más meritoria de la igualdad y de la diferencia entre los hombres para construir sociedad, a lo cual se refiere Camps (1996): "Sabemos, por otra parte, que la identidad no se daría sin la diversidad y la diferencia. Podemos decir "yo" porque hay "otros" iguales a mí y, a la vez, distintos" (p. 147). El ser distintos, pero con la misma participación activa, hace de la política un concepto que depende de la pluralidad y de los hechos constantes que hacen que la acción sea una condición humana que permite la existencia; una existencia que radica en el reconocimiento y en la apertura de nuevos mundos identitarios y políticos a través de la dialéctica y de la vida de cada hombre, ejerciendo en la esfera pública esa importancia y esa trascendencia política que se ha constituido en el actuar juntos. Es así, que el ser distintos no supone una diferencia magna para entenderse y comprenderse, sino que otorga un conocimiento vasto para compartirlo y vivirlo con los demás.

La política de lo diverso pretende demostrar la propia política de la vida que asevera la diferencia con los "otros" y sumerge en las pretensiones de la existencia humana y en la claridad de lo que es vivir en la esfera pública; el aislamiento del mundo, típico del totalitarismo obstruye, el "llegar a ser alguien", como lo afirma Camps, en el espacio y en el tiempo en el cual se desempeña. La vida y el actuar juntos no se pueden coartar en el orbe contemporáneo, y menos en la época contemporánea que profundiza en los aspectos de la aceptación y la igualdad que se han propuesto desde los asuntos humanos; la política de lo diverso confirma una vez más que se está vivo y se es parte de una sociedad dinámica y metamórfica en el tiempo, la cual no puede distanciar de la pluralidad y de la convergencia del actuar como un colectivo vivo y que pretende la equidad en la reflexión de los pensamientos y de los aportes políticos que el colectivo propone.

\section{Visión antropológica de una política de la vida}

Con la política de la muerte los totalitarismos europeos incidieron en el exterminio de la dignidad humana y en toda acción emergente de la pluralidad que se propusiera desde la unión de los hombres; la finitud de los hombres en campos de concentración, lager o gulag, demostró una vez más la presencia del Estado represor y su exterminio ilimitado por medio de la violencia y de la barbarie en contra de esa humanidad fragmentada en religiones, grupos étnicos, grupos políticos, entre otros.

La visión antropológica de la política de la muerte reveló las muertes de tipo físico y político que se efectuaron en estos regímenes. El exterminio de la vida física y el aislamiento de la vida política se pudieron demostrar en ese periodo de entreguerras, acaecido en la ruina y en la destrucción de un continente europeo plagado de cambios políticos y bélicos. La política de la vida en cambio está inmersa a partir de la condición humana, sobre todo, la condición humana de la acción que profesa la pluralidad, la justicia, la libertad, la dialogicidad, las emociones y los consensos departidos desde el actuar juntos. La visión antropológica de la política de la vida se basa en la existencia misma de los hombres en el mundo, es por ello que Hannah Arendt, en su texto La condición humana, destaca la trascendencia de la aparición ante los otros y la importancia de la vida misma en el mundo. La labor, el trabajo y la acción invitan a la vida y al permanecer en el mundo como un colectivo que tiene una esfera privada, pero que hace parte de una esfera pública, la cual facilita la igualdad y la identidad por fuera del aislamiento y de la muerte.

Un comienzo nuevo para una acción nueva hace a ese hombre un ser capacitado para acciones políticas innovadoras. El estar en la esfera pública y relacionarse a través del discurso es empezar a vivir el momento individual, pero también el momento social que exige el ámbito de lo público en consonancia con la libertad y la apertura de la acción. La vida propia de los seres humanos promulga su participación en el espacio para constatar la habilidad del diálogo y de los contratos sociales que se ejecutan o se han ejecutado a través de la historia. El nuevo comienzo de una vida por medio de la natalidad propuesta por Arendt es esperar un futuro que puede ser fijado por la condición humana de la acción y de la supervivencia de la pluralidad dentro de esa política de la vida que acepta nuevas permutas y diversidades en los asuntos humanos.

El hombre, como ese ser que ha destilado la política en su trasegar histórico, confiere cierta expresión a la humanidad propiciadora de menesteres públicos y de poner al margen todo acontecimiento descrito a partir de las decisiones que se toman en grupo. La política de la vida descubre esos acontecimientos gracias a la acción y al discurso de los cuales hacen parte los hombres. La política de la muerte llegó a generar esa ausencia de pensamiento en los hombres del totalitarismo y a legitimar las acciones políticas de Estado como paradigmas centrales de autoridad y exterminio hacia aquellos que eran diferentes en su etnicidad, en sus credos e ideologías; por lo tanto, esa política de la muerte mengua la cosmovisión de vida que ha sido obstaculizada por esa metafísica de imaginaciones totalitarias con respecto al oprobio de destruir y confinar la vida física y la vida humana en el mundo.

\section{Conclusiones}

La política de la vida a través de la diversidad y la pluralidad indica que la condición humana es prioritaria para que la existencia de la vida de los hombres sea plural y política, una política que junto con la dialogicidad infiera en contextos sociales y configure a la acción como la principal hacedora de nuevos conocimientos y nuevas lógicas discursivas. El hombre es elemental para que la condición 
humana trascienda en el mundo, también, es indispensable que su especie se traduzca no solo como una humanidad referida a la tradición histórica, sino como hombres que se reconocen en una misma esfera pública por medio de su diversidad y su pluralidad con respecto al aparecer y a un nuevo comienzo desde el colectivo, el cual precise un acontecimiento político que fluya en el porvenir de la vida humana.

El estar juntos propone una diversidad radicada en la trascendencia política y en las formas plurales de dignificar a la vida humana, llevando a cabo la inmanencia de las relaciones públicas y del reconocimiento taxativo por medio del pensar y del actuar políticamente.

La política de la vida concede efervescencia y vitalidad a la esfera pública y a los asuntos humanos, primando la universalidad de la condición humana y la libertad de los hombres dentro de un espacio y un tiempo que procuren la infinitud del estar en el entre-nos y de reivindicar al espacio público dentro de una pluralidad.

La política de la muerte impartió una barbarie sin escrúpulos dentro de un tiempo histórico determinado. El nacionalsocialismo y el estalinismo como ideologías de base cumplieron el objetivo de exterminar a la vida humana y reducirla a lo mínimo en términos materiales y políticos, por lo tanto, una política de la muerte lleva a establecer la crueldad y la sin razón para coartar la condición humana y la pluralidad de los hombres en un contexto beligerante.

El fin de la política de la vida es contrarrestar esa barbarie por medio de un reconocimiento plural que subyace en la esfera pública y que legitima las diversas cosmovisiones individuales; el ámbito político de la pluralidad lleva a concretar la aparición ante ese otro que espera y determina lo superlativo de la esfera pública en la condición humana de la acción, es así que dentro de ese espacio que se concibe como público se busca el reconocimiento, las decisiones y las claridades que ofrece la política de la vida, una política que debe ser certera en términos éticos y que se apoye en la diversidad humana, una diversidad que lleva a sus espaldas la responsabilidad y trascendencia de la condición humana.

\section{Referencias}

Arendt, H. (2005). La condición humana. Barcelona: Editorial Paidós.

Arendt, H. (2012). La vida del espíritu. Barcelona: Editorial Paidós.

Arendt, H. (1995). De la historia a la acción. Barcelona: Editorial Paidós.

Aristóteles. (trad. 1993). La política. Barcelona: Ediciones Altaya.

Camps, V. (1996). Virtudes públicas. Madrid: Espasa-Calpe.

Engels, F. (1978). El papel del trabajo en la transformación del mono en hombre. Medellín: Ediciones Los Comuneros.

Hegel, F. (1978). Fenomenología del espiritu. México D.F.: Fondo de Cultura Económica.

Marx, K. (1984). El capital. Barcelona: Ediciones Orbis.

Mèlich, J. (2012). Filosofía de la finitud: Barcelona: Herder Editorial.

\section{@() $\Theta($}

